\title{
The spectrum of autopsy in a tertiary referral center in Eastern Nepal
}

This article was published in the following Dove Press journal:

Research and Reports in Forensic Medical Science

31 October 2013

Number of times this article has been viewed

\author{
Nuwadatta Subedi' \\ BN Yadav² \\ Shivendra $\mathrm{Jha}^{3}$ \\ Deepa Shah ${ }^{3}$ \\ Utsav Shrestha ${ }^{3}$ \\ Anil Sharma ${ }^{3}$ \\ Mrityunjay K Rai ${ }^{3}$ \\ 'Department of Forensic Medicine, \\ College of Medical Sciences, \\ Bharatpur, Chitwan, ${ }^{2}$ Department \\ of Forensic Medicine, ${ }^{3} \mathrm{BP}$ Koirala \\ Institute of Health Sciences, Dharan, \\ Nepal
}

Background: Autopsy is examination of a body post-mortem, with a view to determining the cause of death. Performing an autopsy has benefits for many parties: the family of the deceased, the clinician and hospital, and society at large.

Materials and methods: The materials of the study were medico-legal autopsies $(n=458)$ carried out by the Department of Forensic Medicine and Toxicology, BP Koirala Institute of Health Sciences between 15th July 2008 and 14th July 2009 (one fiscal year in Nepal). Autopsy reports were reviewed and interpreted in terms of the cause and manner of death, and demographic parameters.

Results: The maximum number of reported cases was in the 21-30 years age group. The sex ratio of cases was 1.6:1 (M:F). The majority of deceased were from rural areas (60\%), followed by urban areas (40\%). There was no appreciable variation in the numbers of autopsies with respect to month of the year, or day of the week. Most deaths were either accidental $(48.25 \%)$ or suicidal (40.83\%). Homicide and natural causes accounted for $9.18 \%$ and $1.74 \%$ of deaths, respectively.

Conclusion: The group most commonly affected was the young, productive age group, predominantly male. The majority of deaths were accidental or suicidal. Road traffic accident was the leading cause of accidental death. Poisoning was the leading method of suicide. Physical assault with blunt object was the most common cause of homicidal death.

Keywords: accident, autopsy, Eastern Nepal, homicide, suicide

\section{Introduction}

Autopsy is examination of a body post-mortem, with a view to determining the cause of death. ${ }^{1}$ Although medical conventions and legal systems vary considerably from country to country, there are, generally, two main types of autopsy: clinical (or academic) autopsy and medico-legal (or forensic) autopsy. According to Nepalese law, a medico-legal autopsy is performed as part of an inquest. This generally involves deaths associated with violent crime, including mechanical interference with respiratory passages, physical assault, and poisoning. In addition, all deaths that occur suddenly, or under suspicious circumstances, are referred for autopsy. ${ }^{2}$

Autopsy is used not only for determining the cause of death and contributing factors. As a mechanism for medical quality control, it has a multifaceted role, which includes 1) confirmation, clarification, and correction of ante-mortem clinical diagnoses, 2) verification of diagnoses made by newer investigative techniques, 3 ) evaluation of performance of surgical and medical management, and 4) monitoring of possible adverse effects. ${ }^{3}$ It is very distressing for the family of the deceased not to
Correspondence: Nuwadatta Subedi Department of Forensic Medicine, College of Medical Sciences, Bharatpur, Chitwan, Nepal Tel +977985505 4563

Email subedind@yahoo.com 
know which disease deprived them of their loved one. For families, the autopsy has both tangible and psychological benefits. Uncertainty regarding the cause of an individual's death can delay payment of insurance benefits. Autopsy can also uncover genetic or environmental causes of disease (eg, a bacterium or fungus) that could affect other family members. Autopsy is a mechanism that enables participation in medical education and research. Autopsy findings can be utilized to educate physicians, nurses, residents, and students, thereby contributing to improved quality of care.

Our study objectives were to analyze the demographics of death cases, the cause, and manner of death.

\section{Materials and methods}

This was a hospital-based retrospective observational study, conducted at the Department of Forensic Medicine and Toxicology, BP Koirala Institute of Health Sciences (BPKIHS), Dharan, Nepal. It included 458 medico-legal autopsies, performed between 15th July 2008 and 14th July 2009 (one fiscal year in Nepal). The records of autopsies performed at BPKIHS mortuary, and relevant inquest papers, were retrieved and analyzed with respect to sociodemographic parameters, cause, and manner of death.

In each case, detailed post-mortem examination was performed. Bodies were examined externally, and all injuries and deformities were noted, with regard to location, dimension, and orientation. All body cavities (cranium, thorax, abdomen, and pelvis) were opened, and all injuries and pathologies of organs were noted in detail. In all known and suspected cases of poisoning, viscera were preserved and sent for toxicological analysis to the Central Police Forensic Science Laboratory, Kathmandu. The identification of poisons was determined on the basis of toxicological analysis of viscera and any available samples of the poison.

The BPKIHS Department of Forensic Medicine and Toxicology deals with most of the medico-legal cases in Sunsari District, and cases referred from different parts of the eastern region of Nepal. All data were compiled using Microsoft Excel (Microsoft Corporation, Redmond, WA, USA), and analyzed using SPSS version 17.0 software (IBM Corporation, Armonk, NY, USA). Observations were recorded, analyzed, and discussed.

\section{Results}

A total of 458 autopsies were conducted during the study period. It was observed that the maximum number of autopsy examinations was in the $21-30$ years age group, contributing $139(30.34 \%)$ cases. The $31-40$ years age group was the next largest, contributing 90 (19.65\%) cases. Manner of death in relation to age group is shown in Table 1. It was observed that most subjects belonged to rural communities, contributing $275(60 \%)$ cases, while the remaining $183(40 \%)$ cases were urban dwellers.

Table 2 shows the sex distribution of autopsy cases in relation to manner of death. Cases involved males $(n=284$, $62.01 \%)$ more often than females ( $n=174,37.99 \%)$; the maleto-female ratio was 1.6:1. In a majority of cases, the manner of death was either accidental (48.25\%) or suicidal (40.83\%). Homicide (9.18\%) and natural causes (1.74\%) accounted for only a few deaths. Among accidental and homicidal deaths, males outnumbered females, whereas females were involved more often in suicidal deaths.

The distribution of cases in relation to month of the year is shown in Figure 1. We observed that the months of June and July produced fewer cases, compared to other months.

The causes of accidental deaths are shown in Figure 2, which reveals that road traffic accident (RTA) is the most common cause (76.92\%). Burning (6.78\%), drowning (5.88\%), and falling from a height (4.97\%) were other common causes of accidental death. When the type of road user was factored among RTA deaths, pedestrians $(32.53 \%)$ were the majority. Table 3 shows RTA deaths in relation to type of road user.

Table 4 shows suicide totals by method and sex. Among 187 suicidal deaths, poisoning contributed 65.77\%,

Table I Age distribution of cases, with manner of death

\begin{tabular}{|c|c|c|c|c|c|}
\hline Age group (years) & Accidental n (\%) & Suicidal n (\%) & Homicidal n (\%) & Natural n (\%) & Total n (\%) \\
\hline $0-10$ & II (4.98) & $0(0)$ & $0(0)$ & $3(37.5)$ & $14(3.05)$ \\
\hline $11-20$ & $39(1.64)$ & $42(22.45)$ & $7(16.67)$ & $0(0)$ & $88(19.210)$ \\
\hline $21-30$ & 59 (26.69) & $65(34.75)$ & $14(33.34)$ & $\mathrm{I}(12.5)$ & $139(30.34)$ \\
\hline $31-40$ & $49(22.17)$ & $32(17.11)$ & $7(16.67)$ & $2(25)$ & $90(19.65)$ \\
\hline $4 I-50$ & $25(\mid I .3 I)$ & $17(9.09)$ & $6(14.28)$ & I (I2.5) & $49(10.69)$ \\
\hline $51-60$ & $14(6.33)$ & $19(9.84)$ & $6(14.28)$ & $0(0)$ & $39(8.510)$ \\
\hline $6 I-70$ & $14(6.33)$ & $10(5.34)$ & I (2.38) & I (I2.5) & $26(5.67)$ \\
\hline$>70$ & $10(4.52)$ & $2(1.06)$ & I (2.38) & $0(0)$ & $13(2.83)$ \\
\hline Total & $221(100)$ & $187(100)$ & $42(100)$ & $8(100)$ & $458(100)$ \\
\hline
\end{tabular}


Table 2 Distribution of manner of death, with respect to sex

\begin{tabular}{llll}
\hline Manner of death & Male & Female & $\begin{array}{l}\text { Total } \\
\mathbf{n}(\%)\end{array}$ \\
\hline Accidental & 165 & 56 & $221(48.25)$ \\
Suicidal & 87 & 100 & $187(40.83)$ \\
Homicidal & 27 & 15 & $42(9.18)$ \\
Natural or undetermined & 5 & 3 & $8(1.74)$ \\
Total $(\%)$ & $284(62.01 \%)$ & $174(37.99 \%)$ & $458(100)$ \\
\hline
\end{tabular}

followed by hanging (28.87\%), and burning (4.27\%); all were more frequent in female suicides. Jumping from a height was a method used by two males to commit suicide. Agents of poisoning are shown in Table 5. In the vast majority of cases, agricultural insecticides were involved: organophosphates $(46.34 \%)$ and organochlorides (11.38\%). Alcohol and medicinal drugs (in the form of sedatives, morphine, and non-steroidal anti-inflammatory drugs) were each the agent in $8.13 \%$ of deaths. Among the vegetable poisons involved in $4.87 \%$ of deaths, Datura fastuosa and Cerbera thevetia were each involved in three cases of poisoning.

As shown in Figure 3, among 42 homicidal deaths, the leading cause was physical assault with blunt object (71.42\%), followed by assault with a sharp weapon, then firearm injury, each contributing $14.28 \%$ of cases.

\section{Discussion}

This study was undertaken to determine the autopsy trends at BPKIHS, which is a focal autopsy center of the eastern region of Nepal. All 458 autopsies, performed during one year, were analyzed after reviewing case reports. These autopsies reflected violent and unnatural deaths; they are performed in in Nepal following apparently unnatural deaths.
Our study showed a higher number of male than of female cases. This is similar to other studies, which also report male predominance..$^{4-7}$ Our cases were mostly young people in the prime, productive years of their lives; their deaths affect the productivity of their society. This younger age group is more likely to be involved in risk-taking behavior as well as to be experiencing developmental pressures. Measures should be taken to prevent untimely death in this, most vibrant, segment of Nepalese society.

Most of the deaths reported in our study were either accidental or suicidal. Homicide and other causes accounted for $9.18 \%$ and $1.72 \%$, respectively. This accords with the findings of an earlier study from Kathmandu. ${ }^{4}$ Studies from Pakistan ${ }^{6}$ and Nigeria ${ }^{7}$ reported that homicidal deaths constituted the majority of deaths referred for autopsy. Our lower percentage reflects the fact that homicide is less common in Nepal. The rate of incarceration in Nepal is one of the lowest in the world. ${ }^{8}$ The reason homicide rates are higher in other countries could be lack of confidence in the judicial system, with people tending to take the law into their own hands, for settling differences and disputes in their local settings. Although the homicide rate in Nepal is lower than in other countries, it can still be lessened through properly delivered counseling, to develop positive attitudes and control aggression in young people. Our study found a lower frequency of natural death discovered at autopsy, compared with other studies. ${ }^{4,7}$ In one similar study from Bharatpur, Nepal, no natural death was reported..$^{5}$ Our study shows an extremely low proportion of natural deaths amongst medico-legal autopsies, which implies that more cases should be subjected to medico-legal autopsy, in order not to overlook homicides, suicides, and

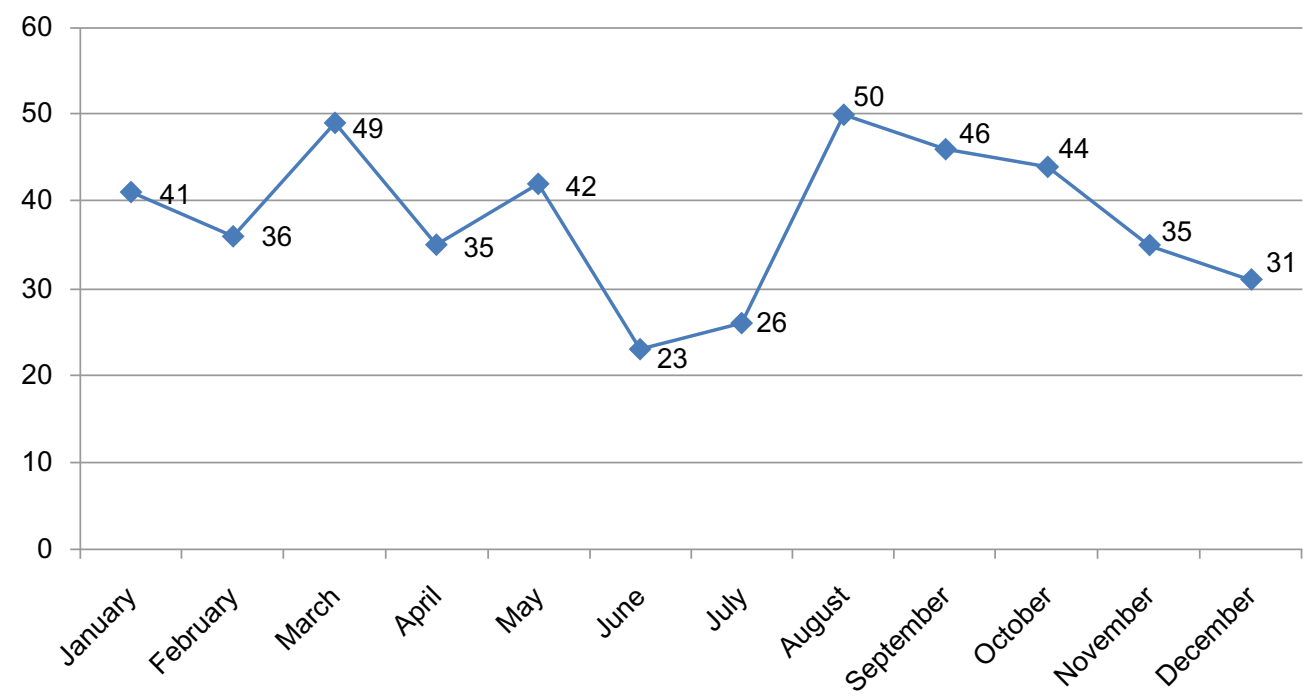

Figure I Monthly distribution of cases. 


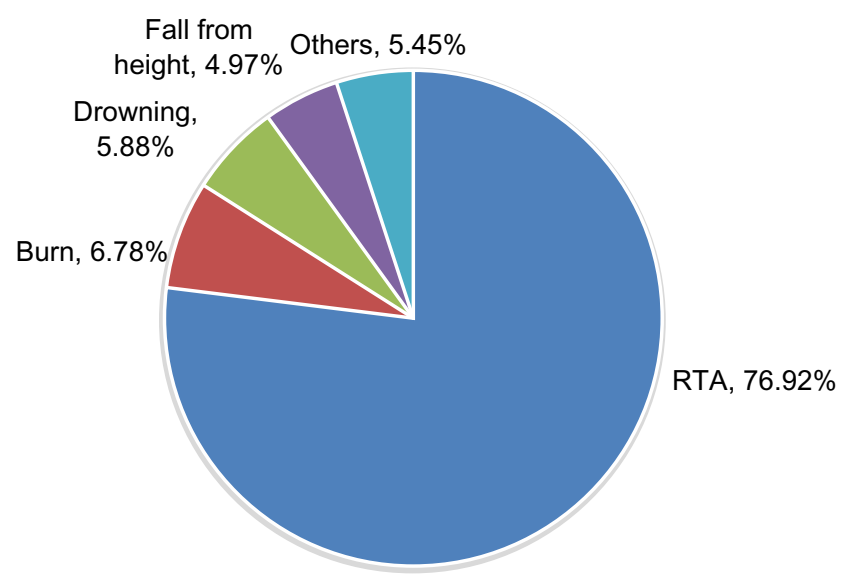

Figure 2 Causes of accidental death.

Abbreviation: RTA, road traffic accident.

accidental deaths. Therefore, rather than performing autopsy only in apparently unnatural deaths, all suspicious and sudden deaths should be subjected to medico-legal autopsy.

We found that most cases of accidental or homicidal death were male, whereas most cases of suicidal death were female, and that all were most common in the 21-30 years age group. Our findings regarding accidental and homicidal deaths are in accord with those of a study conducted by Nwosu et al in Nigeria. ${ }^{9}$ In contrast with our findings, other studies from Nigeria, ${ }^{10}$ and India, ${ }^{11}$ found that suicidal deaths were more common among males. This could be due to differences in research settings. In our study, the lesser involvement of females in accidental and homicidal deaths could be attributed to their confinement within homes, protecting them from being involved in violence. In our context, the greater number of suicides among females could be explained by the fact that, in many Nepalese communities, women are confined at home and restricted from enjoying the freedoms of their male counterparts. Furthermore, many men abandon their families for long periods to work, often abroad, leaving their wife alone in a state of separation and distress.

In respect of accidental deaths, RTA was found to be the major cause, most commonly affecting the $21-30$ years age group. Other, similar studies from Nepal have reported comparable results. ${ }^{4,5,12}$ This situation is a universal issue, because

Table 3 Distribution of victims of road traffic accidents

\begin{tabular}{ll}
\hline Type of road user & $\mathbf{n}(\%)$ \\
\hline Pedestrian & $149(32.53 \%)$ \\
Motorcyclist or driver & $127(27.72 \%)$ \\
Passenger & $71(15.50)$ \\
Pillion rider & $60(13.10 \%)$ \\
Cyclist & $51(11.13 \%)$ \\
Total & $458(100 \%)$ \\
\hline
\end{tabular}

Table 4 Method of committing suicide, with respect to sex

\begin{tabular}{llll}
\hline Methods of suicide & Male & Female & Total $\mathbf{n}(\%)$ \\
\hline Poisoning & 58 & 65 & $123(65.77)$ \\
Hanging & 25 & 29 & $54(28.87)$ \\
Burn & 2 & 6 & $8(4.27)$ \\
Fall from height & 2 & 0 & $2(1.69)$ \\
Total & 87 & 100 & $187(100)$ \\
\hline
\end{tabular}

of traffic overloading worldwide. In our context, the high incidence of RTA deaths could be due to poor enforcement of traffic rules and regulations, drunk driving, and the intricate, twisting, winding nature of roads in the hilly regions of Nepal. The high proportion of young adults affected could be due to their high levels of activity, as they are the most economically active segment of the population. Because human error is the cause of most accidents, ${ }^{13,14}$ there is a need for greater awareness and public education regarding RTA hazards. Poorly maintained roads (like narrow ditches), and crowding on the highways, need to be properly monitored and maintained. Pedestrians and cyclists should be separated from vehicular traffic by cycle lanes, and pedestrian overpasses and sidewalks. Incremental gains in public awareness should be sought (eg, pedestrian and drunk driving education). To prevent fatality from treatable injury, the quality and quantity of first aid services should be improved, by training local volunteers; effectiveness in managing injured victims can be improved through training medical staff and emergency medical services to respond steadily and appropriately at an incident.

This study reveals that most suicidal deaths were caused by poisoning, followed by hanging. This accords with the finding of a study from Malaysia, which showed that poisoning and hanging were the most preferred methods of suicide. ${ }^{15}$ We found that agricultural chemicals (organophosphates and organochlorides) were the poisons ingested most frequently for the purpose of suicide. This is explained by the fact that in Nepal, an agricultural country with a lack of strict regulation over the sale of these chemicals, such poisoning agents are

Table 5 Causes of poisoning death

\begin{tabular}{ll}
\hline Type of poison & Total $\mathbf{n}(\%)$ \\
\hline Organophosphate & $57(46.34)$ \\
Organochloride & $14(11.38)$ \\
Alcohol & $10(8.13)$ \\
Medicinal drugs & $10(8.13)$ \\
Zinc phosphide & $7(5.69)$ \\
Vegetable poison & $6(4.87)$ \\
Kerosene & $3(2.43)$ \\
Unknown/unidentified & $16(13.01)$ \\
Total & $123(100)$ \\
\hline
\end{tabular}




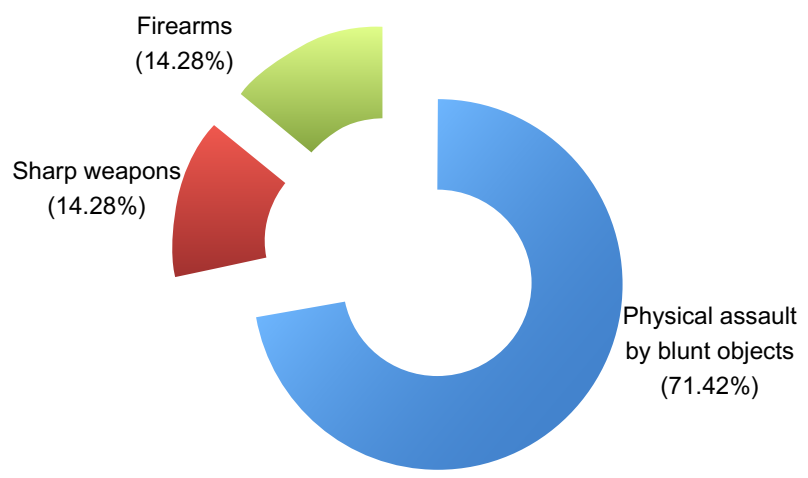

Figure 3 Causes of homicidal death.

easily accessible. Studies from other South Asian countries also show the main agents in poisonings to be agricultural chemicals. ${ }^{16-19}$ The pattern of poisoning deaths in developed countries contrasts strikingly with that of developing countries. Nearly all of poisoning deaths in the United States are attributed to drugs, mostly resulting from abuse of prescription and illegal drugs. ${ }^{20} \mathrm{~A}$ study from Palestine showed that the majority of intentional poisonings involved pharmaceutical agents. ${ }^{21}$

Identifying, and reducing the availability of, and access to means of suicide (such as insecticide poison and drug overdose) demands strict legal scrutiny over the provision of these compounds, which may, in turn, limit their availability. Studies have shown that restricting the availability of pesticides (by banning potentially toxic poisons) goes a long way towards reducing the number of deaths due to poisoning. ${ }^{22,23}$ Legal action against those attempting or abetting suicide should be taken. Most importantly, vulnerable people in society should be identified, counseled, and encouraged to work, to overcome their frustrations in life.

Cases of alleged accidental or suicidal death due to burning might relate to "dowry deaths", but factual histories were not provided. As dowry death is not mentioned in law in Nepal, investigating authorities are not obliged to explore whether or not a death is associated with dowry.

We have revealed that physical assault was the most common cause of death in Nepal, followed by assault with sharp weapons, and firearms. These findings contrast with those of studies conducted in Pakistan ${ }^{6}$ and Nigeria, ${ }^{7}$ which found that firearms were the most common causal agents in homicide. This could be attributed to the greater accessibility of firearms in those areas, owing to the prevalence of armed conflict and high levels of gun possession.

\section{Conclusion}

Our study has made an attempt to garner, from medico-legal reports, the spectrum of autopsies in Eastern Nepal. The most commonly affected group was the young, productive age group, with males more often involved than females. The majority of deaths were either accidental or suicidal. RTA was the most common cause of accidental death. Poisoning was the leading method of suicide. Physical assault with blunt object was the most common cause of homicidal death.

Medico-legal autopsy reports can serve as important tools for understanding fatalities from violence and injury. An autopsy has benefits for many parties: the families of the deceased, clinicians and hospitals, and society as a whole.

\section{Disclosure}

The authors report no conflicts of interest in this work.

\section{References}

1. Vij K. Textbook of Forensic Medicine and Toxicology. 4th ed. New Delhi, India: Elsevier; 2001.

2. Government of Nepal, Ministry of Law, Justice and Parliamentary Affairs. Country code of Nepal (1963). Kathmandu, Nepal: Bauddik Darpan; 2010.

3. De Villiers FPR, Ruhaya M. Students' opinions on autopsy and death. SA Fam Pract. 2005;47(1):47-50.

4. Sharma G, Shrestha PK, Wasti H, Kandel T, Ghimire P, Dhungana S. A review of violent and traumatic deaths in Kathmandu, Nepal. Int J Inj Contr Saf Promot. 2006;13(3):197-199.

5. Prasad BK, Prasad C. Road traffic accident (RTA) as major killer: a report on medico-legal autopsies in Bharatpur hospital. Kathmandu Univ Med J (KUMJ). 2003;1(1):34-35.

6. Marri MZ, Bashir MZ, Munawar AZ, Khalil ZH, Khalil IU. Analysis of homicidal deaths in Peshawar, Pakistan. J Ayub Med Coll Abbottabad. 2006;18(4):30-33.

7. Seleye-Fubara D, Nwosu SO. Violent deaths in Port Harcourt, Nigeria Niger J Surg Res. 2003;5(3-4):124-128.

8. Hartney C. US Rates of Incarceration: A Global Perspective. Oakland, CA: National Council on Crime and Delinquency; 2006.

9. Nwosu SO, Odesanmi WO. Pattern of suicides in Ile-Ife, Nigeria. West Afr J Med. 2001;20(3):259-262.

10. Kanchan T. Menezes RG. Suicidal hanging in Manipal, South India victim profile and gender differences. J Forensic Leg Med. 2008;15(8): 493-496.

11. Akhiwu WO, Nwosu SO, Aligbe JU. Homicide and suicide in Benin City, Nigeria; Anil Aggarwal's Internet Journal of Forensic Medicine and Toxicology. Jun 2006; 1(2). Available from: http://www. anilaggrawal.com/ij/vol_001_no_002/paper001.html.

12. Subedi N, Yadav BN, Jha S, Paudel IS, Regmi R. A profile of abdominal and pelvic injuries in medico-legal autopsy. J Forensic Leg Med. 2013;20(6):792-796.

13. Mishra B, Sinha Mishra ND, Sukhla S, Sinha A. Epidemiological study of road traffic accident cases from Western Nepal. Indian J Community Med. 2010;35(1):115-121.

14. Odero W, Khayesi M, Heda PM. Road Traffic Injuries in Kenya: magnitude, causes and status of intervention. Inj Control Saf Promot. 2003;10(1-2):53-61.

15. Nadesan K. Pattern of suicide: a review of autopsies conducted at the University Hospital, Kuala Lumpur. Malays J Pathol. 1999;21(2): 95-99.

16. Khan NA, Rahman A, Sumon SM, et al. Pattern of poisoning in a tertiary level hospital. Mymensingh Med J. 2013;22(2):241-247.

17. Hettiarachchi J, Kodithuwakku GC. Pattern of poisoning in rural Sri Lanka. Int J Epidemiol. 1989;18(2):418-422. 
18. Howlader MAR, Sardar MH, Amin MR, et al. Clinico-epidemiological pattern of poisoning in a tertiary level hospital. J Dhaka Med Coll. 2008;17(2):111-115.

19. Batra AK, Keoliya AN, Jadhav GU. Poisoning: an unnatural cause of morbidity and mortality in rural India. J Assoc Physicians India. 2003;51:955-959.

20. Paulozzi LJ, Ballesteros MF, Stevens JA. Recent trends in mortality from unintentional injury in the United States. J Safety Res. 2006;37(3): $277-283$.
21. Sawalha AF, Sweileh WM, Tufaha MT, Al-Jabi DY. Analysis of the pattern af acute poisoning in patients admitted to a governmental hospital in Palestine. Basic Clin Pharmacol Toxicol. 2010;107(5): 914-918.

22. Konradsen F, van der Hoek W, Cole DC, et al. Reducing acute poisoning in developing countries - options for restricting the availability of pesticides. Toxicology. 2003;192(2-3):249-261.

23. Loevinsohn ME. Insecticide use and increased mortality in rural central Luzon. Lancet. 1987;1(8546):1359-1362.

\section{Publish your work in this journal}

Research and Reports in Forensic Medical Science is an international, peer-reviewed, open access journal publishing original research, reports, reviews and commentaries on all areas of forensic medical science. The manuscript management system is completely online and includes a

very quick and fair peer-review system. Visit http://www.dovepress.com/ testimonials.php to read real quotes from published authors. 